\title{
Ion channels, guidance molecules, intracellular signaling and transcription factors regulating nervous and vascular system development
}

\author{
Tenpei Akita ${ }^{1}$ (D) Tatsuro Kumada ${ }^{2} \cdot$ Sei-ichi Yoshihara ${ }^{3} \cdot$ Joaquim Egea $^{4} \cdot$ \\ Satoru Yamagishi ${ }^{5}$
}

Received: 30 September 2015/ Accepted: 30 September 2015/Published online: 27 October 2015

(C) The Physiological Society of Japan and Springer Japan 2015

\begin{abstract}
Our sophisticated thoughts and behaviors are based on the miraculous development of our complex nervous network system, in which many different types of proteins and signaling cascades are regulated in a temporally and spatially ordered manner. Here we review our recent attempts to grasp the principles of nervous system development in terms of general cellular phenomena and
\end{abstract}

All authors contributed equally to this work in providing an comprehensive review of different aspects of the subject.

The topics discussed in this review were presented at the symposium entitled "New trends for research on the regulatory mechanism of neuronal development" during the joint meeting of the 120th Annual Meeting of the Japanese Association of Anatomists and the 92nd Annual Meeting of the Physiological Society of Japan, held at Kobe Convention Center on 23 March 2015.

Tenpei Akita

tenpak@hama-med.ac.jp

1 Department of Neurophysiology, Hamamatsu University School of Medicine, 1-20-1 Handayama, Higashi-ku, Hamamatsu, Shizuoka 431-3192, Japan

2 Department of Occupational Therapy, Faculty of Health and Medical Sciences, Tokoha University, 1230 Miyakoda-cho, Kita-ku, Hamamatsu, Shizuoka 431-2102, Japan

3 Laboratory for Molecular Biology of Neural System, Advanced Medical Research Center, Nara Medical University, 840 Shijo-cho, Kashihara, Nara 634-8521, Japan

4 Molecular and Developmental Neurobiology Group, Biomedical Research Institute of Lleida (IRBLleida), University of Lleida, 25198 Lleida, Spain

5 Department of Anatomy and Neuroscience, Hamamatsu University School of Medicine, 1-20-1 Handayama, Higashi-ku, Hamamatsu, Shizuoka 431-3192, Japan molecules, such as volume-regulated anion channels, intracellular $\mathrm{Ca}^{2+}$ and cyclic nucleotide signaling, the Npas4 transcription factor and the FLRT family of axon guidance molecules. We also present an example illustrating that the same FLRT family may regulate the development of vascular networks as well. The aim of this review is to open up new vistas for understanding the intricacy of nervous and vascular system development.

Keywords Nervous system development · Anion channel - Intracellular signaling · Transcription factor . Axon guidance $\cdot$ Vascular system development

\section{Introduction}

The nervous system has a complex but highly organized structure, providing the basis for our complex and sophisticated thoughts and behaviors. The development of the nervous network system is thus nothing short of a miracle, with many different kinds of proteins and signaling cascades being up- and downregulated in a temporally and spatially ordered manner during this process. One effective approach to gaining an understanding of the principles of nervous system development is to explore commonalities and variations in general cellular phenomena and molecules. In this review, we focus on the functions of ion channels, intracellular calcium ion $\left(\mathrm{Ca}^{2+}\right)$ and cyclic nucleotide signaling, transcription factors and axon guidance molecules to understand the rules of nervous system development. Interestingly, we also describe how some of these rules are applicable to the development of vascular networks as well. Our aim is to open up new vistas for understanding the intricacy of nervous and vascular system development. 


\section{Roles of volume-regulated anion channels during neuronal migration in the developing brain}

During proliferation, migration, neurite extension and retraction, among other processes, the cell volume of developing neurons changes dynamically. Cell volume regulation is an essential function in all types of cell and is achieved through regulation of the net influx or efflux of solutes, which is accompanied by passive water movement, across the plasma membrane. The volume-sensitive outwardly rectifying (VSOR) anion channel is a major regulator of anion flux during cell volume regulation and is present on all types of vertebrate cells as the most dominant form of volume-regulated anion channels [1-5]. The VSOR channel is activated in response to cell swelling induced by hypotonic or excitotoxic stimuli or, alternatively, to receptor activation without cell swelling. Opening of the channel provides anions, mainly chloride ions $\left(\mathrm{Cl}^{-}\right)$, with a pathway through the cell membrane, which in turn may induce either the net influx or net efflux of solutes across the membrane with the help of the electrochemical driving forces of other cations, such as sodium $\left(\mathrm{Na}^{+}\right)$ions for influx or potassium ions $\left(\mathrm{K}^{+}\right)$for efflux; this process results in an increase or a decrease in cell volume, respectively. The VSOR channel is also permeable to excitatory amino acids, such as glutamate and aspartate, and as such may also play a role in signaling between adjacent cells, especially in the central nervous system (CNS) [5, 6]. Activation of the VSOR channel through triggering by receptor activation is regulated in the immediate vicinity of the activated receptor molecules. In earlier studies carried out by our group (T. Akita) in astrocytes, this activation was found to be mediated by $\mathrm{Ca}^{2+}$-dependent kinases that are activated in regions containing a very high concentration of intracellular $\mathrm{Ca}^{2+}$ within nanometers of the $\mathrm{Ca}^{2+}$-permeable ion channelsthe so-called $\mathrm{Ca}^{2+}$ nanodomains [7,8]. This mechanism provides a basis for selective activation of a limited number of VSOR channels located on a part of the cell surface where a small number of receptors are locally activated, and it is this local activation which may drive the changes in local cell volume required for morphological changes of the cell [5].

Biophysical and pharmacological characteristics of the VSOR anion channel differ somewhat between cell and tissue types $[3,5]$. These characteristics and the roles of the channel have been well explored in the mature CNS, whereas they are still poorly understood in the immature nervous system [5]. Critical roles of the VSOR anion channel in cell proliferation, migration, differentiation and programmed cell death have been elucidated during development in other biological systems [9-11], strongly indicating that it also plays critical roles during nervous system development, as recently found during cerebral cortex development. There are two major streams of neuronal migration in the developing cortex: tangential migration of gamma-aminobutyric acid (GABA)ergic interneurons originating from the ganglionic eminences in the ventral forebrain and radial migration of glutamatergic pyramidal and spiny stellate neurons from the adjacent ventricular zone lining the dorsal telencephalic ventricles in the fetal brain (Fig. 1a). It has long been suggested that GABA released from migrating interneurons regulates the speed of radial migration of glutamatergic neurons [12-15]. We recently confirmed that blockade of $\mathrm{GABA}_{\mathrm{A}}$ receptors with SR95531 accelerates radial migration [16], leading to the conclusion that activation of $\mathrm{GABA}_{\mathrm{A}}$ receptors slows the migration, presumably for proper development of the cerebral cortex. Interestingly, we further found that the major endogenous agonist of $\mathrm{GABA}_{\mathrm{A}}$ receptors during the radial migration is taurine released through the VSOR channels from neurons-and not GABA [16]. Taurine is known to act as an agonist of the receptors for glycine and GABA [17-19]. In the mature brain, the cytoplasm of both neurons and glia contain taurine at concentrations of $10-20 \mathrm{mM}$ [20], whereas in the embryonic brain the taurine content is five- to tenfold higher [21, 22]. We also observed that taurine is enriched in the marginal zone (MZ) and in the subplate (SP) of the fetal neocortex [16] (Fig. 1b), suggesting that both the CajalRetzius neuron in the MZ and the SP neuron secrete taurine. Permeability of the VSOR channel to taurine has been demonstrated in mature neurons and glia [23-26] and, more recently, also in neural stem/progenitor cells obtained from both embryonic and adult brains [21]. However, the mechanism of just how VSOR channels are activated to release taurine during the radial migration is not yet resolved. Activation of $\mathrm{GABA}_{\mathrm{A}}$ receptor $\mathrm{Cl}^{-}$channels depolarizes the membrane of migrating embryonic neurons due to their reversal voltage for $\mathrm{Cl}^{-}$ being higher than their resting membrane voltage [27], and this induces the opening of voltage-gated $\mathrm{Ca}^{2+}$ channels and intracellular oscillatory $\mathrm{Ca}^{2+}$ signaling [12, 15, 27]. If the VSOR channels located at the leading edges of migrating neurons are activated through $\mathrm{Ca}^{2+}$ nanodomains of the oscillatory signaling process, the resulting $\mathrm{Cl}^{-}$efflux with the help of $\mathrm{K}^{+}$efflux would promote shrinkage of the edges. Therefore, taurine-mediated $\mathrm{GABA}_{\mathrm{A}}$ receptor activation might enhance VSOR 

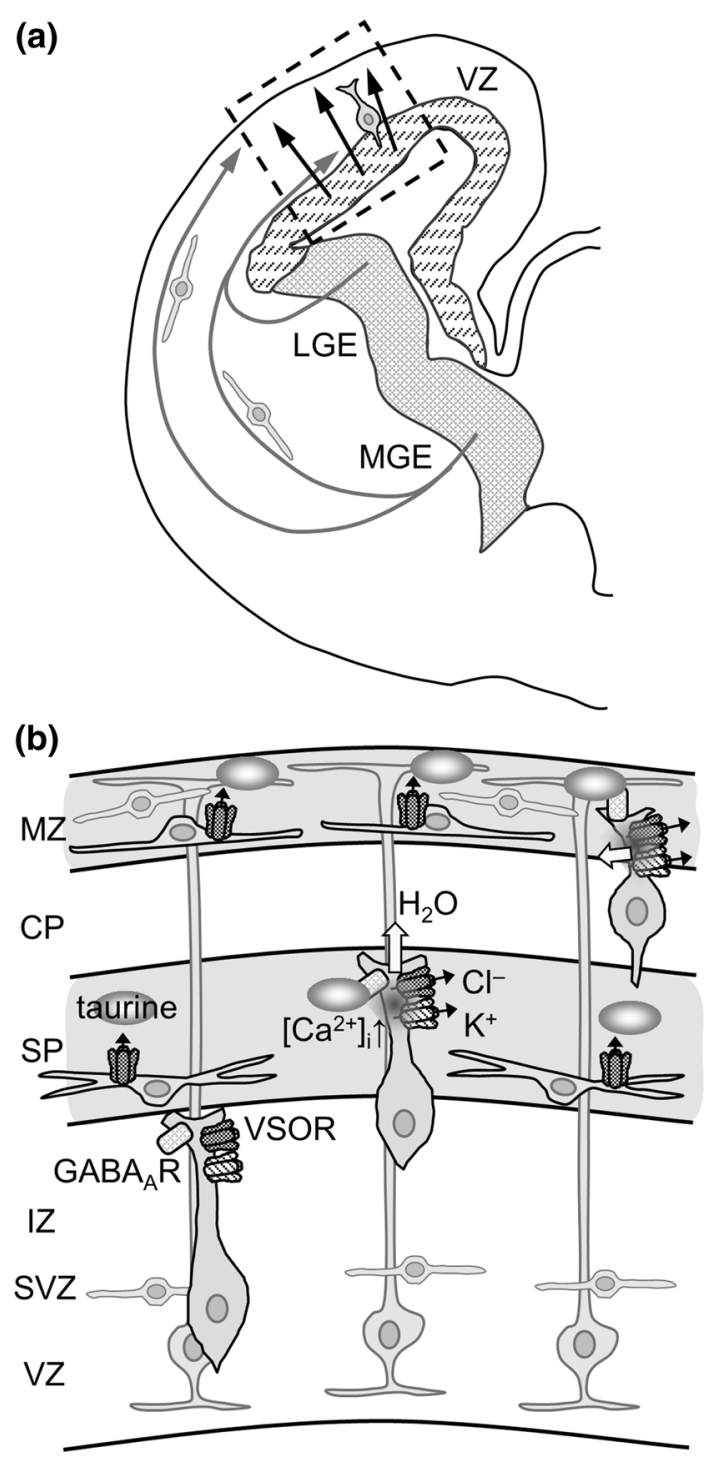

channel activation at the edges of migrating neurons when the edges reach the taurine-rich regions, and this might put a brake on the migration ("VSOR channel hypothesis"; Fig. 1b).

As a regulator of cell volume and intercellular signaling, the VSOR anion channel is likely to play important roles not only in radial migration, but also in tangential migration, proliferation and differentiation of the networks of neurons and glia in the developing brain. It has been demonstrated that normal brain assembly in embryos, including cortical layer formation, axonal fiber projection and morphological synapse formation, depends on neurotransmitters that must be released through as yet unidentified mechanisms that differ from vesicular exocytosis [28, 29]. Therefore, exploring in detail the modes of activation of the VSOR channel and how these relate to the developing processes would shed light on the mystery of fetal brain development in the near future.
4Fig. 1 Two major routes of neuronal migration and the volumesensitive outwardly rectifying (VSOR) channel hypothesis in the developing cerebral cortex. a Schematic of the routes of radial migration of glutamatergic neurons (black arrows) originating from the ventricular zone (VZ) and tangential migration of gammaaminobutyric acid (GABA) ergic interneurons (gray arrows) from the lateral and medial ganglionic eminences ( $L G E$ and $M G E$, respectively). A half of a coronal section of the forebrain at about embryonic days 15-17 (E15-17) in mice is depicted. The dashed box indicates the region discussed in b. b "VSOR channel hypothesis" during the radial migration. Taurine is released through VSOR anion channels from the cells, particularly those located in the marginal zone $(M Z)$ and the subplate $(S P)$ [16]. Most of newly born glutamatergic neurons in the $\mathrm{VZ}$ at this embryonic stage migrate along the vertical fibers of the radial glial cells (leftmost column). When the leading edges of migrating neurons reach the taurine-rich SP zone (middle column) and MZ (rightmost column), taurine binds to and activates $\mathrm{GABA}_{\mathrm{A}}$ receptors $\left(G A B A_{A} R\right)$ in the migrating neurons [16], and this increases the frequency of oscillatory rises in the intracellular calcium ion concentration $\left(\left[\mathrm{Ca}^{2+}\right]_{i}\right)$. It may be hypothesized that these rises in $\left[\mathrm{Ca}^{2+}\right]_{i}$ would trigger VSOR channel activation and the net efflux of chloride ions $\left(\mathrm{Cl}^{-}\right)$, potassium ions $\left(\mathrm{K}^{+}\right)$and water $\left(\mathrm{H}_{2} \mathrm{O}\right)$ across the cell membrane, thereby slowing down the migration and shrinking the leading edges. $C P$ Cortical plate, $I Z$ intermediate zone, $S V Z$ subventricular zone

\section{Control of neuronal migration by extrinsic and intrinsic programs through modulating $\mathrm{Ca}^{2+}$ and cyclic nucleotide signaling}

Newborn neurons often exhibit spontaneous elevations of intracellular $\mathrm{Ca}^{2+}$ level. In this section, T. Kumada discusses results showing that both extrinsically and intrinsically determined patterns of intracellular $\mathrm{Ca}^{2+}$ fluctuations and their interactions with cyclic nucleotide signaling control the speed, mode and direction of neuronal migration. Komuro and Rakic originally demonstrated the relationship between $\mathrm{Ca}^{2+}$ fluctuations and neuronal migration using time-lapse $\mathrm{Ca}^{2+}$ imaging of granule cells migrating from a microexplant of the postnatal cerebellum in culture [30]. These authors noted that the amplitude and frequency of $\mathrm{Ca}^{2+}$ transients in isolated granule cells are positively correlated with the rate of cell movement. In the cerebellar tissue, granule cells change their mode of migration during their trajectory; after they tangentially migrate at the fastest rate in the external granular layer, they change the direction from tangential to radial toward the internal granular layer, where they terminate their migration [31] (Fig. 2a). Using cerebellar slice culture preparations, Kumada and Komuro confirmed that granule cells exhibited distinct patterns of $\mathrm{Ca}^{2+}$ transients and rates of cell movement in different cerebellar cortical layers, that the frequency of $\mathrm{Ca}^{2+}$ transients was indeed positively correlated with the migration speed during the whole trajectory and finally that the $\mathrm{Ca}^{2+}$ transients ceased before termination of their 
migration [32, 33] (Fig. 2a). Increasing and decreasing the frequency of $\mathrm{Ca}^{2+}$ transients by experimentally altering the $\mathrm{Ca}^{2+}$ influx increased and decreased the migration speed, respectively, and experimentally eliminating the $\mathrm{Ca}^{2+}$ transients induced a premature termination of migration [32]. Thus, the results confirmed that the layerspecific pattern of $\mathrm{Ca}^{2+}$ transients controls the speed of granule cell migration in each cortical layer. Similar regulation has also been reported in tangentially migrating GABAergic interneurons in the developing neocortex [34]. However, in contrast to these observations, an increase in $\mathrm{Ca}^{2+}$ oscillation frequency has been shown to induce termination of the radial migration of glutamatergic neurons in the developing neocortex $[15,35,36]$. $\mathrm{Ca}^{2+}$ signaling dynamically interacts with the signaling cascades mediated by other second messengers, such as cyclic adenosine monophosphate (cAMP) [37]. By pharmacologically manipulating cAMP and cyclic guanosine monophosphate (cGMP) levels, our group revealed that cAMP signaling acts as a brake on granule cell movement, while cGMP signaling acts as an accelerator [38]. Activation of cAMP signaling decreases the frequency of $\mathrm{Ca}^{2+}$ transients, and this is one of the causes of the decrease in granule cell motility, while activation of cGMP signaling does not affect this frequency [39].

Depolarizing neuronal activity mediated by neurotransmitters increases the frequency of $\mathrm{Ca}^{2+}$ transients through activation of voltage-gated $\mathrm{Ca}^{2+}$ channels (VGCC), and this may regulate neuronal development prior to synaptogenesis [40, 41]. Komuro and Rakic were the first to show that the N-type VGCC and the NMDA ( $N$-methyl-D-aspartate) subtype of glutamate receptor facilitate granule cell migration in the cerebellar tissue [42, 43]. In immature neurons, GABA also acts as an excitatory neurotransmitter and increases the $\mathrm{Ca}^{2+}$ transient frequency through VGCC activation [15, 27, 35]. The excitatory GABA action is based on raised intracellular $\mathrm{Cl}^{-}$concentrations due to $\mathrm{Cl}^{-}$ uptake through the $\mathrm{Na}^{+}-\mathrm{K}^{+}-\mathrm{Cl}^{-}$cotransporter 1 (NKCC1) in immature neurons [44]. Developmental or experimental expression of $\mathrm{Cl}^{-}$-extruding $\mathrm{K}^{+}-\mathrm{Cl}^{-}$cotransporter 2 (KCC2) converts the excitatory action of GABA into an inhibitory action, which reduces the $\mathrm{Ca}^{2+}$ fluctuation frequency and may vary the mode of neuronal migration [34, $45,46]$. This developmental switch in the action of GABA is controlled by cell-intrinsic programs during neuronal differentiation [47]. In addition to VGCC, the release of $\mathrm{Ca}^{2+}$ from internal $\mathrm{Ca}^{2+}$ stores is also involved in the regulation of neuronal migration [48]. Although $\mathrm{Ca}^{2+}$ signaling is known to play a pivotal role in organizing the cytoskeleton, precise detailed knowledge of just how $\mathrm{Ca}^{2+}$ signaling determines the dynamic behavior of developing neurons and the mode of neuronal migration is still lacking.

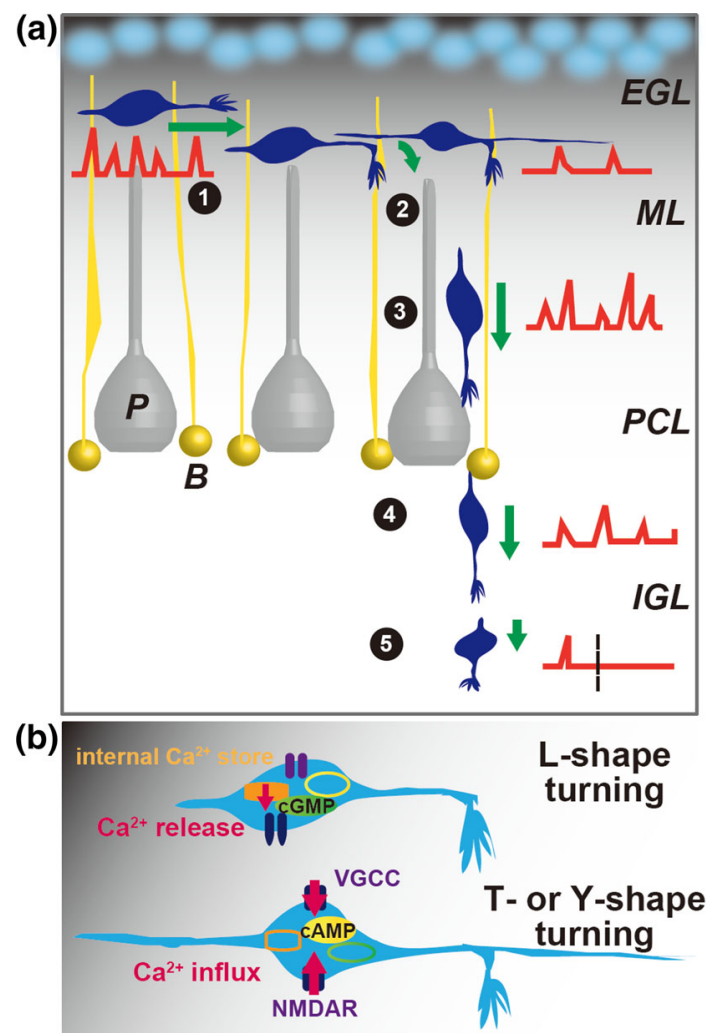

Fig. 2 Control of cerebellar granule cell migration by $\mathrm{Ca}^{2+}$ transients and cyclic nucleotide signaling in a layer-specific manner. a Schematic diagram showing the relationship between the sequence of cerebellar granule cell migration and the pattern of $\mathrm{Ca}^{2+}$ transients. 1-5 enclosed within black circles Stages of granule cell differentiation as it proceeds in ascending order along the migratory pathway: 1 the cell tangentially migrates at the fastest rate in the external granular layer $(E G L), 2$ the cell changes the direction of migration from tangential to radial, i.e. turns, in two different modes at the boundary between EGL and the molecular layer $(M L), 3$ the cell radially migrates along the Bergmann glial process, 4 the cell radially migrates within the internal granular layer $(I G L), 5$ the cell completes migration at the bottom of the IGL. Green arrow at each stage indicates the direction of migration, and its length reflects the migration speed. Red traces Typical patterns of $\mathrm{Ca}^{2+}$ transients at corresponding stage. The speed positively correlates with the frequency of $\mathrm{Ca}^{2+}$ transients. The mode of turning at stage 2 is determined as shown in b. At stage 5, the migration terminates approximately $10 \mathrm{~min}$ after loss of $\mathrm{Ca}^{2+}$ transients. Dotted line in the $\mathrm{Ca}^{2+}$ trace Time of termination. b Different modes of granule cell turning controlled by $\mathrm{Ca}^{2+}$ and cyclic nucleotide signaling at stage 2 . Stimulating $\mathrm{Ca}^{2+}$ release from internal $\mathrm{Ca}^{2+}$ stores or cyclic guanosine monophosphate ( $c G M P$ ) signaling increases the occurrence of $L$-shape turning, which is characterized by turning of the tip of the leading process to a new direction. Movement of the soma follows the direction of the tip turning. In contrast, increasing $\mathrm{Ca}^{2+}$ influx via the voltage-gated $\mathrm{Ca}^{2+}$ channel $(V G C C)$ or glutamate receptors $(N$ methyl-D-aspartate receptor, $N M D A R$ ) or stimulating cyclic adenosine monophosphate ( $c A M P)$ signaling increases the occurrence of $T$ or $Y$-shape turning, characterized by bifurcation of the leading process [55]. The relationship between the turning modes and the $\mathrm{Ca}^{2+}$ or cyclic nucleotide signaling is essentially the same as that in isolated granule cells [55] (color figure online) 
External cues provided by axon guidance molecules are also known to play important roles in neuronal migration. Some guidance molecules, such as Slit, may induce $\mathrm{Ca}^{2+}$ elevation in the leading processes of migrating neurons in a manner similar to that observed in axonal growth cones [48-50]. Slit-2, a chemorepellent to cerebellar granule cell migration, induces a propagating $\mathrm{Ca}^{2+}$ wave from the leading process to the soma, which is mediated by $\mathrm{Ca}^{2+}$ induced $\mathrm{Ca}^{2+}$ release from the internal stores [49]. Sonic hedgehog, another guidance molecule, also acts as an important trigger of $\mathrm{Ca}^{2+}$ signaling-mediated neural activity, inducing neuronal differentiation [51]. These processes suggest the importance of links between individual external cues and distinct modes of $\mathrm{Ca}^{2+}$ signaling. At specific turning points, the migrating neurons may change their responsiveness to an external cue, as seen in axonal guidance [52]. Interestingly, the intracellular balance between $\mathrm{Ca}^{2+}$ levels and different cyclic nucleotide signaling activities may determine the responsiveness of the migrating neuron to a guidance cue. For example, in embryonic spinal neurons of Xenopus laevis, a higher ratio of cAMP/cGMP in response to netrin-1 binding to DCC (deleted in colorectal cancer) increases $\mathrm{Ca}^{2+}$ currents through VGCCs and intracellular $\mathrm{Ca}^{2+}$ release, resulting in growth cones being attracted to the guidance cue, whereas a lower ratio in response to netrin-1 binding to the DCCUnc5 complex decreases the $\mathrm{Ca}^{2+}$ currents and $\mathrm{Ca}^{2+}$ release, resulting in repulsion from the cue [53].

In addition to external cues, which are essential for the selection of migratory paths, cell-intrinsic programs also control neuronal migration. The speed and mode of migration of isolated granule cells dynamically change even without cell-cell contact and in the absence of external guidance cues $[54,55]$. The migrating isolated cells exhibit autonomous changes in the direction of migration (i.e. turning) and in the shape of their leading and trailing edges. The changes can be subdivided into several distinct modes of turning, and the cellular morphology in each mode is similar to that observed in the cerebellar tissue [55] (Fig. 2b). Thus, the changes must be regulated by cell-intrinsic (internal clock) programs, and we have found that $\mathrm{Ca}^{2+}$ and cyclic nucleotide signaling cascades are also involved in these programs $[39,55]$. For example, in isolated granule cells, the frequency of $\mathrm{Ca}^{2+}$ transients, which positively correlates with their migration rate, depends on the elapsed time after plating, and termination of their migration is always preceded by a loss of $\mathrm{Ca}^{2+}$ transients, as occurs after $50-60 \mathrm{~h}$ of migration in the cerebellar tissue [32] (Fig. 2a). Importantly, experimental manipulations of $\mathrm{Ca}^{2+}$ and cyclic nucleotide signaling pathways in isolated cells vary the speed of migration, the frequency of turning and the preference for a turning mode in the same way as in the tissue [55] (Fig. 2b). Thus, the
$\mathrm{Ca}^{2+}$ and cyclic nucleotide signaling cascades driven by intrinsic programs regulate the autonomous turnings of migrating granule cells in isolated conditions. The mechanism by which the intrinsic programs drive the signaling cascades, however, remains to be elucidated. The autonomous changes in $\mathrm{Ca}^{2+}$ and cyclic nucleotide signaling by intrinsic programs suggest that the programs may also affect the role of external guidance molecules in directing neuronal migration through regulating the basal activity of these signaling pathways. The mechanism of just how intrinsic programs interact with external cues through $\mathrm{Ca}^{2+}$ and cyclic nucleotide signaling is an important issue which needs to be addressed.

Taken together, $\mathrm{Ca}^{2+}$ and cyclic nucleotide signaling not only mediate the responses to external guidance cues, but they also modulate the responsiveness to guidance cues and control neuronal migration even in the absence of external cues based on cell-intrinsic programs. The intrinsic programs may change the role of external guidance molecules by altering $\mathrm{Ca}^{2+}$ and cyclic nucleotide signaling pathways. Thus, both the speed and the fate of neuronal development must be determined by orchestrated interactions between intrinsic programs and external cues through $\mathrm{Ca}^{2+}$ and cyclic nucleotide signaling.

\section{Transcription factor neuronal Per/Arnt/Sim domain protein 4 (Npas4) regulates sensory experience-dependent development of dendritic spines in newborn olfactory bulb interneurons}

Sensory experience regulates neural development in a variety of species and in various brain structures, including the cortex, hippocampus and olfactory bulb (OB) [56-59]. OB interneurons are a good model for studying the modification of neural circuits by sensory inputs from the external world during the postnatal stages. OB interneurons are generated throughout life in the subventricular zone, migrate along the rostral migratory stream and differentiate into GABA-releasing inhibitory interneurons, such as granule cells (GCs) and periglomerular cells (PGCs), in the OB [60-64] (Fig. 3a). Olfactory sensory deprivation or, alternatively, an odor-rich environment can promote suppression or acceleration, respectively, of dendritic morphogenesis and spine formation in newborn OB interneurons [65-71]. However, little is known about the molecular players or the precise mechanisms that integrate odor-induced activity with the developmental processes of OB interneurons.

Using DNA microarray technology and in situ hybridization screenings, our group (S. Yoshihara) newly identified a transcription factor coding gene, neuronal Per/ Arnt/Sim domain protein 4 (Npas4), which is expressed in 
(a)

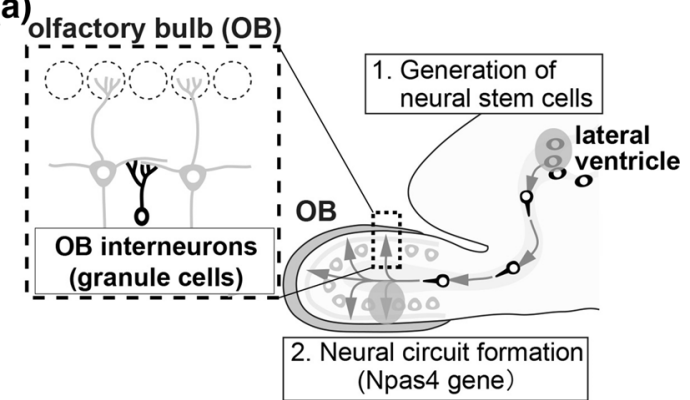

(b)

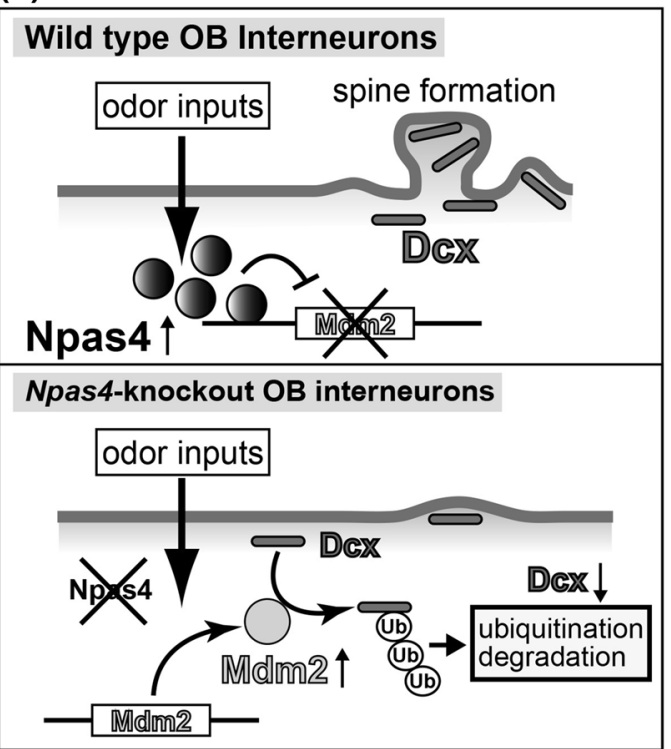

Fig. 3 Odor input-dependent spine formation mediated by the transcription factor neuronal Per/Arnt/Sim domain protein 4 (Npas4) in the olfactory bulb $(O B)$ interneurons. a Neural stem cells that will differentiate into $\mathrm{OB}$ interneurons are generated throughout life in the subventricular zone and migrate along the rostral migratory stream into the $\mathrm{OB}$. After the stem cells arrive at the $\mathrm{OB}$, they differentiate into interneurons and are incorporated into the pre-existing neural circuit. During incorporation, dendritic arbors and spines are formed. b In wild-type OB, odor inputs can induce Npas4 expression, which suppresses the $M d m 2$ expression. The suppression of $M d m 2$ promotes the spine formation of $\mathrm{OB}$ interneurons mediated by doublecortin $(D c x)$. Alternatively in Npas4-knockout OB, loss of Npas4 expression upregulates the expression of $M d m 2$, which ubiquitinates Dcx, leading to the degradation of Dcx and a reduction in the dendritic spine density of $\mathrm{OB}$ interneurons

a subset of OB GCs following sensory experience [71]. Npas 4 is an immediate early gene activated by neuronal activity via $\mathrm{Ca}^{2+}$-dependent signaling pathways [72]. The transcription factor Npas4 promotes the formation of inhibitory synapses in the developing visual system [72] and controls the homeostatic inhibitory/excitatory balance that regulates visual cortical plasticity [73]. Moreover, Npas4 interacts with several promoters that are regulated by neuronal activity and mediates BDNF (brain-derived neurotrophic factor) expression in cortical pyramidal and hippocampal CA3 neurons [72, 74-76]. We performed gain- and loss-of-function experiments for the Npas4 gene in OB GCs, based on lentiviral gene transfer. Npas4 overexpression in newborn OB GCs increased the spine density even under sensory deprivation [71]. Furthermore, Npas4 overexpression increased the number of puncta stained by either post-synaptic [post-synaptic density protein 95 (PSD-95) or gephyrin] or pre-synaptic (synaptoporin) markers in the distal region of GC dendrites [71]. Conversely, both Npas4 knockdown and knockout significantly reduced the spine density of OB GCs [71]. These results strongly suggest that Npas4 is both necessary and sufficient on its own for increasing sensory input-dependent synaptogenesis in OB GCs.

To identify the target genes through which Npas4 regulates synaptogenesis in OB interneurons, we performed ChIP-Seq analysis in homogenized OB tissues using the antibody against Npas 4 and searched for the gene promoter regions that Npas 4 can bind to. As a result, we identified, as a novel target of Npas4, an oncogenic E3 ubiquitin ligase $M d m 2$ gene that is expressed at low levels in the wild-type OB but at higher levels in the Npas4-knockout OB [71]. Thus, we expected that Npas4 would suppress Mdm2 gene expression. The results of gain-of-function and knockdown experiments for $M d m 2$ using the lentiviral vector system showed that overexpression and knockdown of $M d m 2$ reduced and enhanced, respectively, the spine density of GC dendrites compared with controls [71], thereby confirming $M d m 2$ as a bona fide target gene of Npas4 whose expression is indeed suppressed by Npas 4 . To identify the protein targets through which $\mathrm{Mdm} 2$ regulates synaptogenesis in the OB interneurons, we next searched for those proteins expressed differentially between wild-type and two Npas4-knockout OB by iTRAQ quantitative proteomics analysis. Proteomics and cell-line analysis revealed that $\mathrm{Mdm} 2$ ubiquitinates and promotes degradation of a microtubule-associated protein, doublecortin (Dcx) [71]. Immunohistochemistry studies revealed that the expression of Dcx protein in GC dendrites within both the external proximal layer and the GC layer was twofold lower in the Npas4-knockout OB than in the wild-type OB [71]. Furthermore, overexpression and knockdown of $D c x$ using the lentiviral vector system enhanced and reduced, respectively, the spine density of GC dendrites compared with controls [71]. These results reveal that Dcx plays an important role in increasing the dendritic spine density of the OB GCs. Taken together, our findings suggest that Npas4 inhibits Mdm2 expression, which in turn prevents ubiquitination and degradation of Dcx, thereby promoting the development of dendritic spines of OB GCs after sensory experience (Fig. 3b).

To reveal the physiological function of spine formation in OB GCs, we examined the odor discrimination learning 
and memory in OB-specific Npas4-knockout mice generated by the Cre and loxP system. Loss of Npas4 in OB GCs was found to impair the learning of discrimination between two related odors without affecting the olfactory detection ability [71]. This result suggests that spine formation in interneuronal dendrites in the $\mathrm{OB}$ neural circuitry is required for odor-associated learning and memory. Hence, through the regulation of activity-dependent synapse development in OB GCs, Npas4 can play an important role in the formation of functional olfactory learning neuronal circuits.

\section{FLRT3 is a Robo1-interacting protein that determines Netrin-1 attraction in developing axons}

Axon guidance is the process by which axons navigate to encounter their appropriate synaptic partner within the developing nervous system. Together with neuron migration, axon guidance is one of the most important hallmarks of nervous system development, and much study on this process has rendered many important clues of how it is wired and functions. Results obtained from different animal models have revealed many of the basic principles and the molecular mechanisms involved in the process of axon guidance [77-79]. For example, the tip of the axon has a protrusion, called the "growth-cone," which is a very motile structure actively exploring the environment for cues that "guide" the axons to reach the proper target. Many of these axon guidance cues have been characterized, and they include five large families, namely, the Netrin, Slit, Ephrin, Semaphorin and classical morphogen families. These cues are sensed by the growth cone through specific receptors located at the surface of the cone, and the receptors activate intracellular signaling cascades which ultimately modify cytoskeleton dynamics. This leads to an attractive or a repulsive response, depending on the cellular context and the type of axon guidance cue and receptor involved. Axon guidance is not continuous but rather a step-wise process in which axons encounter intermediate targets (e.g. the nervous system midline), where they have to make guidance decisions. One intermediate target affects the response to the next one by changing, for example, the composition of receptors at the surface of the growth cone $[77,80]$. Moreover, the guidance of a particular set of axons is tightly controlled in time and space and very often is exquisitely coordinated with the migration of other axons or neurons [81]. Interestingly, the molecular mechanisms of axon guidance are not restricted to the nervous system, and they have also been found to be involved in the development of other systems, such as the vascular system (see following section).
Strikingly, the number of cues and receptors involved in axon guidance is relatively low compared to the enormous complexity of the nervous system. Mechanisms of proteolytic cleavage of these proteins, posttranslational modifications, alternative splicing or the presence of co-receptors have been described to fine tune and expand the responses of a particular axon to the environment [80, 82, 83]. More recently, it has been reported in many different contexts that the combination of several axon guidance cues triggers a response that cannot be predicted by the response to any of the cues individually, indicating that axon guidance cues are able to crosstalk. The mechanisms underlying such crosstalk are not known, but this is currently a field of very active research in molecular neurobiology since this is a scenario that resembles more accurately the in vivo situation where axons are challenged with a combination of cues [84]. Also, these studies most probably will provide new insights which will further our understanding of the process of axon guidance and nervous system wiring and function. In this section, recent research carried out by our group (J. Egea; see [85] for further information) will be discussed. This work has elucidated the crosstalk mechanism of two of the most well-characterized axon guidance cues, netrin and slit, in the development of the thalamocortical axons (TCAs). TCAs convey sensory (with the exception of olfaction) and motor information to the neocortex. They are arranged topographically, with rostral thalamic neurons projecting their axons into the motor cortex and intermediate and caudal thalamic neurons projecting their axons into the somatosensory and visual cortex, respectively. This arrangement is controlled by gradients of axon guidance cues in a ventral structure called the corridor which sorts the axons according to their final destination [86] (Fig. 4). Rostral TCAs (rTCAs) cross an area in the corridor with the higher expression levels of Netrin, which can be either repulsive if Netrin interacts with Unc5 receptors or attractive if it interacts with DCC receptors, and of Slit, which interacts with Robo receptors, typically triggering repulsion. In order to understand how rTCAs integrate these two signals, we challenged in vitro explant cultures of rostral thalamus with Netrin and Slit, either individually or in combination (Netrin + Slit). Surprisingly, Netrin did not induce any effect, whereas Slit induced repulsion on these axons. Interestingly, Netrin + Slit triggered a net attractive response on rTCAs but not on intermediate axons (iTCAs), a result that may explain the segregation of the two types of projection in vivo [87]. In order to understand the mechanisms involved in the specific attraction of rTCAs towards Netrin + Slit, we performed several in vivo and in vitro experiments. We demonstrated that the axon guidance receptor Robo1, but not Robo2, was necessary for the attractive effect, suggesting that Slit was activating its 


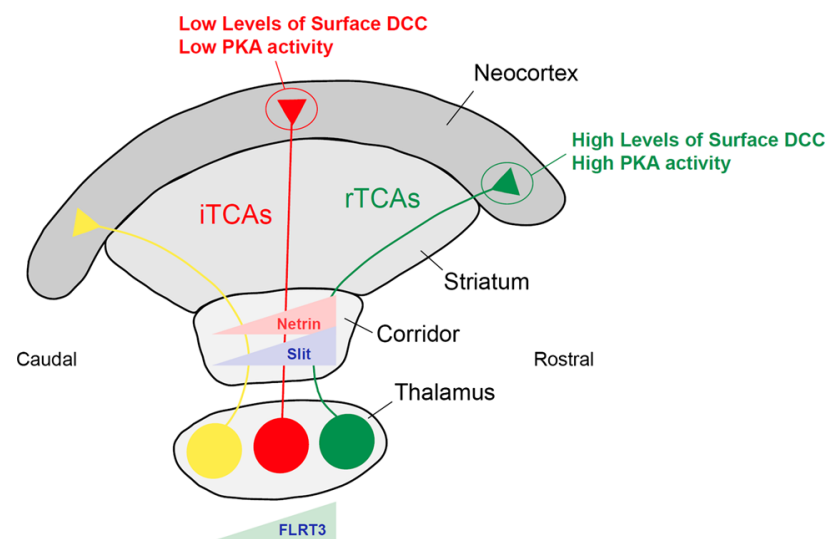

Fig. 4 Integration of Netrin and Slit1 signaling by rostal thalamocortical axons ( $r T C A s)$ at the corridor requires fibronectin leucine-rich transmembrane protein-3 (FLRT3) for proper topographic projection. Schema of a horizontal section of the developing mouse brain showing the topographic distribution of the thalamocortical projections and the gradients from rostral-high to caudal-low of the molecules discussed in the main text: Slit 1 and Netrin in the corridor and FLRT3 in the thalamus. rTCAs require high levels of FLRT3 that in combination with Robol activates protein kinase A $(P K A)$ signaling and triggers an increase in DCC (deleted in colorectal cancer) levels at the surface of the growth cone to permit the attraction of these axons by Netrin towards the rostral neocortex. iTCAs Intermediate axons. Adapted from Leyva-Díaz et al. [85] (color figure online)

canonical receptor in this context. We also observed that Netrin + Slit induced a strong increase of the DCC levels on the surface of the growth cone on rTCAs but not on Robo1 knockout rTCAs, suggesting that Robo1 signaling is required. This effect was specific since it was neither observed after the stimulation with Slit or Netrin individually, nor in iTCAs stimulated with Netrin + Slit. Taken together, these results strongly indicated that increased DCC levels are required for the attractive response triggered by Netrin + Slit in rTCAs. Surprisingly, basal levels of DCC, Robo1 and Unc5 were not different between rTCAs and iTCAs, suggesting that a different molecular identity, specific to rTCAs, was responsible for the different behavior towards Netrin + Slit stimulation between rTCAs and iTCAs. In our search for possible candidates we focused on the family of fibronectin leucine-rich transmembrane proteins (FLRT). This family comprises three members (FLRT1-3), all of which have been shown to be involved in a wide variety of functions, including cell adhesion during morphogenesis of the early mouse embryo [88-90], neuronal differentiation [91, 92], regulation of radial migration of pyramidal cells in the cortex by acting as repulsive cues for Unc5 receptors [93, 94], in the control of tangential dispersion of pyramidal cells in the cortex by homophyllic adhesion [95] and in synapse development [96]. Among these, we observed that FLRT3 displayed a graded expression in the thalamus, from rostral-high to caudal-low. Moreover, we found Robol to be one of the candidates for binding to the intracellular domain of FLRT3 in a yeast-two hybrid screening, an interaction that we were able to confirm by co-immunoprecipitation and co-localization assays in transfected cells and in cultures of rTCAs. Based on these observations, we considered the possibility that FLRT3 could participate in the attraction of rTCAs towards Netrin + Slit. To test this possibility, we used FLRT3 knockout explants and observed that the increase in surface DCC levels upon Slit + Netrin stimulation did not occur in this experimental context and that FLRT3 knockout rTCAs were not attracted to Netrin + Slit, demonstrating that FLRT3 plays a key role in this attractive response. We reasoned that if FLRT3 was sufficient to trigger this effect, overexpression of FLRT3 in iTCAs, where FLRT3 expression is normally low, should lead these axons to respond to Netrin + Slit and acquire the projection behavior of rTCAs. Indeed, when FLRT3 was overexpressed in iTCAs, these axons switched their projection into more rostral areas of the cortex, where usually only rTCAs project. Consistent with this observation, rTCAs were found to be more fasciculated in FLRT3 knockout embryos, with a significant number of axons spreading towards medial parts of the cortex. How FLRT3 regulates the attraction towards Netrin + Slit is not clear, but we believe that the interaction with Robol changes the intracellular signaling in rTCAs in two ways: on the one hand, FLRT3 inhibits Robo1 repulsive signaling (indeed, the observed repulsion effect of rTCAs towards Slit alone is mediated by Robo2 and not by Robo1), while on the other hand, FLRT3 cooperates with Robo1 in the activation of DCC receptor trafficking to the growth cone surface, an effect that requires the activation of protein kinase A (PKA) signaling. We suggest there is a "threshold" of PKA activity that is achieved upon Slit stimulation through Robo1-FLRT3 and this threshold activity may induce an increase (although undetectable) of surface DCC levels. When Netrin is applied, Netrin binding to DCC raises the level of PKA activity sufficiently high to potentiate a positive feedback loop that induces a further increase of DCC, as previously reported [97].

In summary, these results demonstrate the key role of FLRT3 in the control of, specifically, rTCA projections (see Fig. 4). The presence of FLRT3 and the modulation of Robo1 signaling results in Slit being a permissive cue for Netrin to induce attraction. These axons respond to Netrin + Slit in a manner (attraction) that cannot be predicted by the effects of individual cues (Netrin, no effect; Slit, repulsion). This observation reinforces the notion that mechanisms of crosstalk between axon guidance cues are important to expand the repertoire of axonal responses during development of the nervous system. Crosstalk depends on the presence of specific molecular identities as, 
for example, FLRT3 in the rTCAs, which are regulated in time and space. It is important to point out that crosstalk is also context dependent since the same molecules can exert different effects in different tissues. For example, Netrin and Slit interact differently in callosal and commisural axons compared to rTCAs. In callosal axons in the forebrain, DCC, while crossing the midline to project into the contralateral cortex, exerts a hierarchical effect over Robo1 by inhibiting Robo1 signaling to allow crossing of the midline, a territory highly enriched with Slit [98]. In contrast, in the commissural axons of the spinal cord that have crossed the floor-plate, a territory highly enriched with Netrin, into the contralateral side, Robo1 exerts a hierarchical effect over DCC by inhibiting Netrin attraction to avoid re-crossing of axons [99].

\section{Roles of the FLRT and Unc5 protein families proteins in the development of the nervous and vascular systems}

The vasculature forms an elaborated and massive network, much like the nervous system, through which oxygen and nutrients are supplied to all body tissues. During development and remodeling, arteries and veins are first formed by vascular endothelial cells and then supported by smooth muscle cells and pericytes [100, 101]. Tip cells, a subset of endothelial cells, undergo sprouting angiogenesis, leading to the formation of capillaries. Similar to the growth cone in neurons, these cells sense the extracellular environment (e.g. extracellular matrix, growth factors and guidance molecules) to determine their fate (e.g. growth/extension, retraction or diversion). It is well known that canonical axon guidance molecules, such as Netrin and Unc5, Slit and Robo, Semapholins and Neuropilin/Plexin, Ephrin and Eph, are also commonly identified during vascular system development [79, 102].

Unc5 family proteins (Unc5A-D) are known as the receptors for Netrin family proteins to induce axon repulsion during nervous system development (Fig. 5a). In the vascular system, the Unc5B receptor is expressed on endothelial cells, including arterial tip cells (Fig. 5b) [103]. However, the endogenous ligand for Unc5B in the vascular system is still unknown (see below), and its identification has been a major focus of ongoing research in the field of vascular development since the discovery of the importance of Unc5B in vascular morphogenesis more than a decade ago [103]. In this section of the review, potential ligands for Unc5B during vascular development based on the phenotypes of various knockout mice are discussed by S. Yamagishi.

$\mathrm{Lu}$ et al. reported that Unc5B is specifically expressed on the endothelial cells of arteries and that disruption of $U n c 5 B$ genes in the mouse and zebrafish induces an aberrant morphology of tip-cell fillopodia, increased vessel branching and abnormal navigation of vascular network development [103]. Larrivée et al. demonstrated that Unc5B is transiently expressed during the sprouting of capillaries from tumor implants, indicating involvement of Unc5B in angiogenesis [104]. In retinal blood vessels, lossof-function studies using the antibody or gene knockout against $U n c 5 B$ demonstrated hypervascularization [105]. Furthermore, most of the conventional Unc5B knockout mice die because of heart failure at embryonic day (E) 12.5 [103]. Navankasattusas et al. subsequently reported that even selective knockout of $U n c 5 B$ in vascular endothelial cells, using Tie2-Cre mice and Unc5B-floxed mice, is lethal at the same stage as the conventional one because of a placental problem: the number of robust vertical vessel stalks in the placental labyrinth layer is decreased in the conditional Unc5B knockout mice [106]. Taken together, these results support a critical role for Unc5B in vasculature formation. By contrast, although in vitro experiments have shown that classical Unc5B ligands, namely Netrin-1, -4 and Robo-4, exert an Unc5B-dependent repulsive effect on tip cells, knockout mice of these ligands demonstrate only minor hypervascularization [103, 105, 107-109] and do not suffer from heart failure as do Unc $5 B$ knockout mice [103]. These results imply the existence of other endogenous ligands for the Unc5B receptor for proper vascular development.

In the context of nervous system development, in 2011 we identified FLRT2 and FLRT3 as axon guidance molecules that produce a repulsive effect by binding to the Unc5B and 5D receptors (Fig. 5a; see preceding section) [94]. Structural and biochemical bases for the FLRT-Unc5 binding were recently resolved by crystallography and the surface plasmon resonance assay [95]. FLRT2 and FLRT3 are cleaved at their extracellular juxtamembrane region by matrix metalloproteinases, and the ectodomains are shed into the extracellular space (Fig. 5b). Binding of the FLRT2 ectodomain to the Unc5D receptor is a repulsive cue for axon guidance and neuronal migration. At E15.5 in mice, FLRT2 is strongly expressed in the cortical plate of the developing neocortex, while its receptor Unc5D is expressed in multipolar neurons, namely, future upper layer neurons, in the subventricular zone. Knockout of FLRT2 facilitates the radial migration of multipolar neurons whereas overexpression of Unc5D slows the migration [94]. Thus, the repulsive cue produced by the FLRT2Unc5D interaction would slow radial migration. Intriguingly, Unc5D expression in multipolar neurons is transiently downregulated when the neurons migrate through the FLRT2-rich cortical plate, presumably in order to avoid FLRT2 binding [94]. In contrast, FLRT3 is expressed especially in the intermediate zone of the neocortex and the rostral part of the thalamus in E15 mice [85, 95]. Unc5B- 
Fig. 5 a Binding partners of FLRT and Unc5 family proteins. FLRT2, -3, Robo4 and Netrin1, -4 are the ligands for Unc5 receptors inducing repulsive responses in cells. FNIII Fibronectin type III domain, $L R R$ leucine-rich repeat domain. $\mathbf{b}$ Interaction of FLRT2, -3 with Unc5B, -D on blood vessels and neurons. FLRT2, -3 are cleaved by matrix metalloproteinase (at the site indicated by the scissors). Binding of the ligands to Unc5 receptors normally induces repulsive reactions in tip cells and neurons (color figure online) (a)

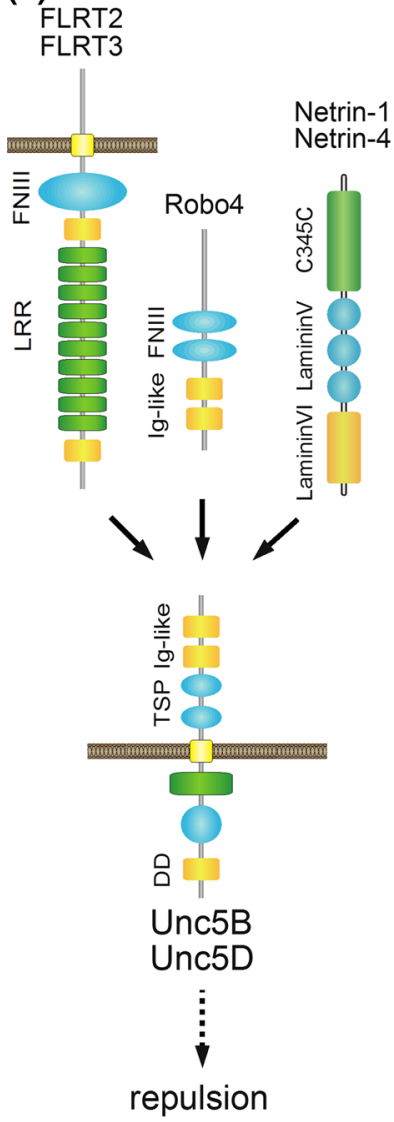

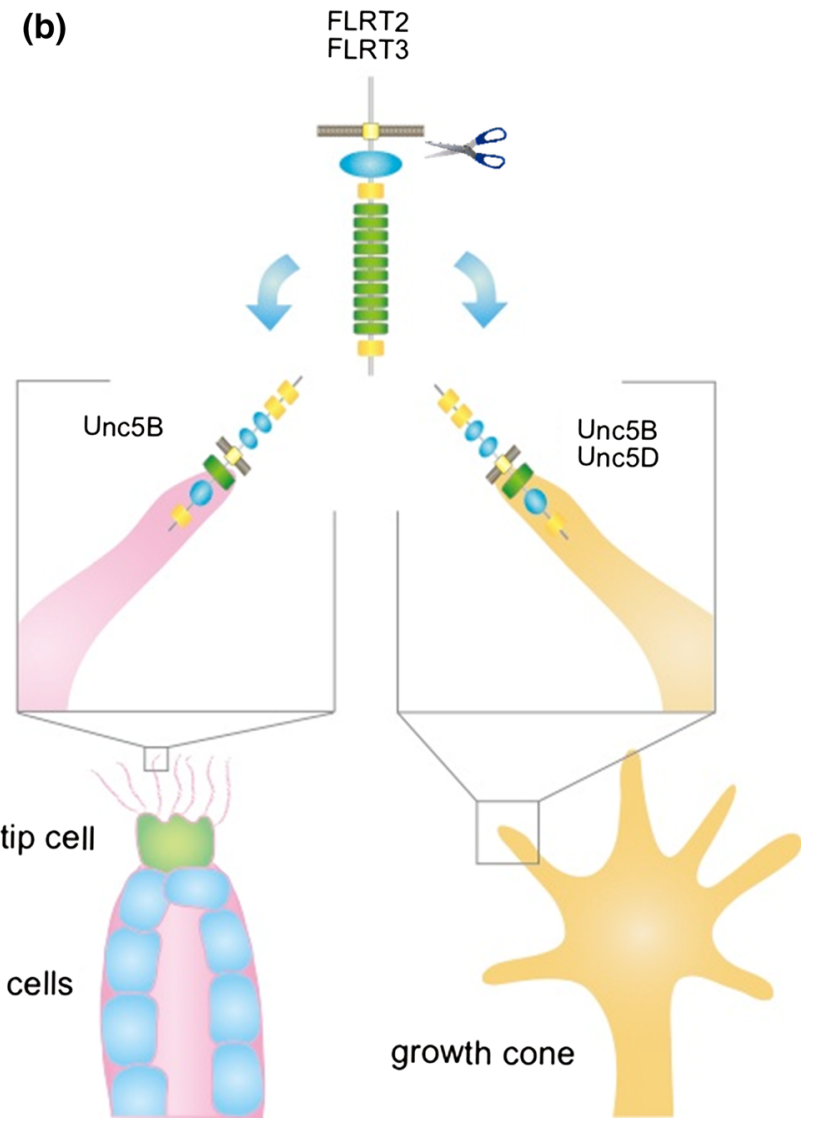

positive thalamic neurons are strongly repelled by FLRT3 [95]. The FLRT3-Robo1 coupling in rostral thalamocortical neurons plays an important role in the proper topographical projection of their axons into the neocortex (see preceding section).

In the embryonic cardiovascular system, FLRT2 is expressed in the epicardial sheet and the myocardium of the heart from E9.5 to birth, whereas FLRT3 is transiently expressed in these structures between E9.5 and E12.5 [90]. FLRT3 is also expressed in the postnatal retina during development of Unc5B-expressing retinal blood vessels [95]. Mice with a loss-of-function mutation in FLRT2 die at E11.5/12.5 due to blood pooling, superficial hemorrhage and pericardial edema [90]. In FLRT2-deficient mice, the basement membrane between the epicardium and the myocardium is disorganized, and the epicardial layer is detached from the myocardium, indicating loss of epicardial integrity [90]. Electron microscopy analysis showed that the surface of the epicardium in the FLRT2 mutant is ruffled and uneven and has small hollows [90]. This phenotype shares similarity with that of the FLRT3 knockout embryo in more primitive embryonic structures, in which the basement membrane in the anterior visceral endoderm is highly disorganized and the hollows on the boundary between the visceral endoderm and the definitive endoderm are visible at the mid-streak stage at around E7 [88]. When FLRT2 was ectopically overexpressed in the FLRT3-deficient embryoid bodies, the basement membrane disorganization was clearly improved [90]. Thus, these results indicate that FLRT2 and FLRT3 have an identical function.

Although both Unc5B and FLRT2 mutant mice die at similar developmental stages, the phenotypes of these mutant mice differ somewhat. For example, the thin heart muscle wall in the FLRT2 mutant is not observed in Unc $5 B$ knockout mice, whereas the placental vascular defect in $U n c 5 B$ knockout mice is absent in the FLRT2 mutant [90, 106]. We have also observed that overexpression of a dominant negative form of Unc5B, lacking its intracellular domain, in arterial endothelial cells in vitro does not block repulsive responses of the cells induced by FLRT2 (unpublished data). Conditional knockout mice of FLRT3, another candidate for the Unc5B ligand, produced using Sox2-Cre, which removes all of the FLRT3 genes in the entire embryo and in the labyrinth layer of the placenta, showed a hypervascular phenotype in the retina, similar to that seen in Unc5B knockout postnatal escaper mice [95, 107]. However, these FLRT3 conditional knockout mice are more likely to be born beyond the critical period when 
most Unc5B knockout mice die [95]. Therefore, neither FLRT2 nor FLRT3 seems to be the unique endogenous ligand for Unc5B. Further analysis using knockout mice of both FLRT2 and FLRT3 or other unknown molecules is needed to identify the endogenous ligand for Unc5B.

\section{Conclusion}

In this review, we have mainly focused on nervous system development and attempted to elucidate its principles in terms of ion channels, intracellular signaling, transcription factors and axon guidance molecules. We have also discussed a similar regulation of vascular system development mediated by the same axon guidance molecules. For each molecular category mentioned in this review, there are a tremendous number of molecular subtypes. Nevertheless, some common schemes and principles can clearly be seen in the modes of crosstalk and interactions between different proteins and/or signaling cascades and also in the modes of cellular movement and morphological changes during the system development. We hope that the topics discussed in this review also provide some clues to the developing processes of other biological systems, such as the lymphatic, respiratory, digestive systems, among others, which are also complex and highly regulated in amazing ways.

Acknowledgments We are grateful to the members of Department of Neurophysiology in Hamamatsu University School of Medicine for useful discussions and suggestions on this work and to Gandhervin Kesavamoorhy for his critical reading and constructive comments on an early version of the manuscript. This work was supported by Grants-in-Aid for Scientific Research from the Japan Society for the Promotion of Science (21790216, 23612008 and 26460293 to T.A.; 2311151023500444 and 26350594 to T.K.; 20163368 and 25430010 to S.Yo.; 23700412, 25122707 and 26670090 to S.Ya.), from the Spanish MICINN (BFU2013-48563-P to J.E.) and from the FP7PEOPLE-2011-CIG (PCIG9-GA-2011-293980 to J.E.). J.E. was a recipient of a short-term fellowship from the Japan Society for the Promotion of Science (S-14197).

\section{Compliance with ethical standards}

Conflict of interest The authors declare that they have no conflict of interest.

\section{References}

1. Strange K, Emma F, Jackson PS (1996) Cellular and molecular physiology of volume-sensitive anion channels. Am J Physiol 270:C711-C730

2. Nilius B, Eggermont J, Voets T, Buyse G, Manolopoulos V, Droogmans G (1997) Properties of volume-regulated anion channels in mammalian cells. Prog Biophys Mol Biol 68:69-119. doi:10.1016/S0079-6107(97)00021-7

3. Okada Y (1997) Volume expansion-sensing outward-rectifier $\mathrm{Cl}^{-}$channel: fresh start to the molecular identity and volume sensor. Am J Physiol 273:C755-C789
4. Okada Y, Sato K, Numata T (2009) Pathophysiology and puzzles of the volume-sensitive outwardly rectifying anion channel. J Physiol 587:2141-2149. doi:10.1113/jphysiol.2008.165076

5. Akita T, Okada Y (2014) Characteristics and roles of the volume-sensitive outwardly rectifying (VSOR) anion channel in the central nervous system. Neuroscience 275:211-231. doi:10. 1016/j.neuroscience.2014.06.015

6. Liu H-T, Akita T, Shimizu T, Sabirov RZ, Okada Y (2009) Bradykinin-induced astrocyte-neuron signalling: glutamate release is mediated by ROS-activated volume-sensitive outwardly rectifying anion channels. J Physiol 587:2197-2209. doi:10.1113/jphysiol.2008.165084

7. Akita T, Okada Y (2011) Regulation of bradykinin-induced activation of volume-sensitive outwardly rectifying anion channels by $\mathrm{Ca}^{2+}$ nanodomains in mouse astrocytes. J Physiol 589:3909-3927. doi:10.1113/jphysiol.2011.208173

8. Akita T, Fedorovich SV, Okada Y (2011) $\mathrm{Ca}^{2+}$ nanodomainmediated component of swelling-induced volume-sensitive outwardly rectifying anion current triggered by autocrine action of ATP in mouse astrocytes. Cell Physiol Biochem 28:1181-1190. doi:10.1159/000335867

9. Lang F, Busch GL, Ritter M, Völkl H, Waldegger S, Gulbins E, Häussinger D (1998) Functional significance of cell volume regulatory mechanisms. Physiol Rev 78:247-306

10. Okada Y, Maeno E, Shimizu T, Dezaki K, Wang J, Morishima S (2001) Receptor-mediated control of regulatory volume decrease (RVD) and apoptotic volume decrease (AVD). J Physiol 532:3-16. doi:10.1111/j.1469-7793.2001.0003g.x

11. Hoffmann EK, Lambert IH, Pedersen SF (2009) Physiology of cell volume regulation in vertebrates. Physiol Rev 89:193-277. doi:10.1152/physrev.00037.2007

12. Behar TN, Li YX, Tran HT, Ma W, Dunlap V, Scott C, Barker JL (1996) GABA stimulates chemotaxis and chemokinesis of embryonic cortical neurons via calcium-dependent mechanisms. J Neurosci 16:1808-1818

13. Behar TN, Schaffner AE, Scott CA, Greene CL, Barker JL (2000) GABA receptor antagonists modulate postmitotic cell migration in slice cultures of embryonic rat cortex. Cereb Cortex 10:899-909. doi:10.1093/cercor/10.9.899

14. Behar TN, Smith SV, Kennedy RT, McKenzie JM, Maric I, Barker JL (2001) GABA $_{B}$ receptors mediate motility signals for migrating embryonic cortical cells. Cereb Cortex 11:744-753. doi:10.1093/cercor/11.8.744

15. Heck N, Kilb W, Reiprich P, Kubota H, Furukawa T, Fukuda A, Luhmann HJ (2007) GABA-A receptors regulate neocortical neuronal migration in vitro and in vivo. Cereb Cortex 17:138-148. doi:10.1093/cercor/bhj135

16. Furukawa T, Yamada J, Akita T, Matsushima Y, Yanagawa Y, Fukuda A (2014) Roles of taurine-mediated tonic $\mathrm{GABA}_{\mathrm{A}}$ receptor activation in the radial migration of neurons in the fetal mouse cerebral cortex. Front Cell Neurosci 8:88. doi:10.3389/ fncel.2014.00088

17. Hussy N, Deleuze C, Pantaloni A, Desarménien MG, Moos F(1997) Agonist action of taurine on glycine receptors in rat supraoptic magnocellular neurones: possible role in osmoregulation. J Physiol 502:609-621. doi:10.1111/j.1469-7793.1997.609bj.x

18. Sergeeva OA, Haas HL (2001) Expression and function of glycine receptors in striatal cholinergic interneurons from rat and mouse. Neuroscience 104:1043-1055. doi:10.1016/S03064522(01)00130-0

19. Albrecht J, Schousboe A (2005) Taurine interaction with neurotransmitter receptors in the CNS: an update. Neurochem Res 30:1615-1621. doi:10.1007/s11064-005-8986-6

20. Walz W, Allen AF (1987) Evaluation of the osmoregulatory function of taurine in brain cells. Exp Brain Res 68:290-298. doi:10.1007/BF00248794 
21. Hernández-Benítez R, Sedeño-Cortés A, Ramos-Mandujano G, Pasantes-Morales H (2014) Regulatory volume decrease in neural precursor cells: taurine efflux and gene microarray analysis. Cell Physiol Biochem 34:2038-2048. doi:10.1159/ 000366399

22. Benítez-Diaz P, Miranda-Contreras L, Mendoza-Briceño RV, Peña-Contreras Z, Palacios-Prü E (2003) Prenatal and postnatal contents of amino acid neurotransmitters in mouse parietal cortex. Dev Neurosci 25:366-374. doi:10.1159/000073514

23. Pasantes-Morales H, Moran J, Schousboe A (1990) Volumesensitive release of taurine from cultured astrocytes: properties and mechanism. Glia 3:427-432. doi:10.1002/glia.440030514

24. Jackson PS, Strange K (1993) Volume-sensitive anion channels mediate swelling-activated inositol and taurine efflux. Am J Physiol 265:C1489-C1500

25. Feustel PJ, Jin Y, Kimelberg HK (2004) Volume-regulated anion channels are the predominant contributors to release of excitatory amino acids in the ischemic cortical penumbra. Stroke 35:1164-1168. doi:10.1161/01.STR.0000124127.57946. a1

26. Haskew-Layton RE, Rudkouskaya A, Jin Y, Feustel PJ, Kimelberg HK, Mongin AA (2008) Two distinct modes of hypoosmotic medium-induced release of excitatory amino acids and taurine in the rat brain in vivo. PLoS ONE 3:e3543. doi:10. 1371/journal.pone.0003543

27. Owens DF, Boyce LH, Davis MB, Kriegstein AR (1996) Excitatory GABA responses in embryonic and neonatal cortical slices demonstrated by gramicidin perforated-patch recordings and calcium imaging. J Neurosci 16:6414-6423

28. Verhage M, Maia AS, Plomp JJ, Brussaard AB, Heeroma JH, Vermeer H, Toonen RF, Hammer RE, van den Berg TK, Missler M, Geuze HJ, Südhof TC (2000) Synaptic assembly of the brain in the absence of neurotransmitter secretion. Science 287:864-869. doi:10.1126/science.287.5454.864

29. Demarque M, Represa A, Becq H, Khalilov I, Ben-Ari Y, Aniksztejn L (2002) Paracrine intercellular communication by a $\mathrm{Ca}^{2+}$ - and SNARE-independent release of GABA and glutamate prior to synapse formation. Neuron 36:1051-1061. doi:10.1016/ S0896-6273(02)01053-X

30. Komuro H, Rakic $P$ (1996) Intracellular $\mathrm{Ca}^{2+}$ fluctuations modulate the rate of neuronal migration. Neuron 17:275-285. doi:10.1016/S0896-6273(00)80159-2

31. Komuro H, Rakic P (1998) Distinct modes of neuronal migration in different domains of developing cerebellar cortex. J Neurosci 18:1478-1490

32. Kumada T, Komuro H (2004) Completion of neuronal migration regulated by loss of $\mathrm{Ca}^{2+}$ transients. Proc Natl Acad Sci USA 101:8479-8484. doi:10.1073/pnas.0401000101

33. Komuro H, Kumada $\mathrm{T}$ (2005) $\mathrm{Ca}^{2+}$ transients control CNS neuronal migration. Cell Calcium 37:387-393. doi:10.1016/j. ceca.2005.01.006

34. Bortone D, Polleux F, Manner VC, Bortone D, Polleux F (2009) $\mathrm{KCC} 2$ expression promotes the termination of cortical interneuron migration in a voltage-sensitive calcium-dependent manner. Neuron 62:53-71. doi:10.1016/j.neuron.2009.01.034

35. Wang T, Kumada T, Morishima T, Iwata S, Kaneko T, Yanagawa Y, Yoshida S, Fukuda A (2014) Accumulation of GABAergic neurons, causing a focal ambient GABA gradient, and downregulation of $\mathrm{KCC} 2$ are induced during microgyrus formation in a mouse model of polymicrogyria. Cereb Cortex 24:1088-1101. doi:10.1093/cercor/bhs375

36. Bando $Y$, Irie $\mathrm{K}$, Shimomura $\mathrm{T}$, Umeshima $\mathrm{H}$, Kushida $\mathrm{Y}$, Kengaku M, Fujiyoshi Y, Hirano T, Tagawa Y (2014) Control of spontaneous $\mathrm{Ca}^{2+}$ transients is critical for neuronal maturation in the developing neocortex. Cereb Cortex. doi:10.1093/cercor/ bhu 180
37. Gorbunova YV, Spitzer NC (2002) Dynamic interactions of cyclic AMP transients and spontaneous $\mathrm{Ca}^{2+}$ spikes. Nature 418:93-96. doi:10.1038/nature00835

38. Kumada T, Lakshmana MK, Komuro H (2006) Reversal of neuronal migration in a mouse model of fetal alcohol syndrome by controlling second-messenger signalings. J Neurosci 26:742-756. doi:10.1523/JNEUROSCI.4478-05.2006

39. Komuro Y, Galas L, Lebon A, Raoult E, Fahrion JK, Tilot A, Kumada T, Ohno N, Vaudry D, Komuro H (2015) The role of calcium and cyclic nucleotide signaling in cerebellar granule cell migration under normal and pathological conditions. Dev Neurobiol 75:369-387. doi:10.1002/dneu.22219

40. Spitzer NC (2006) Electrical activity in early neuronal development. Nature 444:707-712. doi:10.1038/nature05300

41. Rosenberg SS, Spitzer NC (2011) Calcium signaling in neuronal development. Cold Spring Harb Perspect Biol 3:a004259. doi:10.1101/cshperspect.a004259

42. Komuro H, Rakic P (1992) Selective role of N-type calcium channels in neuronal migration. Science 257:806-809. doi:10. 1126/science. 1323145

43. Komuro H, Rakic P (1993) Modulation of neuronal migration by NMDA receptors. Science 260:95-97. doi:10.1126/science. 8096653

44. Yamada J, Okabe A, Toyoda H, Kilb W, Luhmann HJ, Fukuda A (2004) $\mathrm{Cl}^{-}$uptake promoting depolarizing GABA actions in immature rat neocortical neurones is mediated by NKCC1. J Physiol 557:829-841. doi:10.1113/jphysiol.2004.062471

45. Inoue K, Furukawa T, Kumada T, Yamada J, Wang T, Inoue R, Fukuda A (2012) Taurine inhibits $\mathrm{K}^{+}-\mathrm{Cl}^{-}$cotransporter $\mathrm{KCC} 2$ to regulate embryonic $\mathrm{Cl}^{-}$homeostasis via with-no-lysine (WNK) protein kinase signaling pathway. J Biol Chem 287:20839-20850. doi:10.1074/jbc.M111.319418

46. Rivera C, Voipio J, Payne JA, Ruusuvuori E, Lahtinen H, Lamsa K, Pirvola U, Saarma M, Kaila K (1999) The $\mathrm{K}^{+} / \mathrm{Cl}^{-}$cotransporter $\mathrm{KCC} 2$ renders GABA hyperpolarizing during neuronal maturation. Nature 397:251-255. doi:10.1038/16697

47. Kaila K, Price TJ, Payne JA, Puskarjov M, Voipio J (2014) Cation-chloride cotransporters in neuronal development, plasticity and disease. Nat Rev Neurosci 15:637-654. doi:10.1038/ nrn3819

48. Zheng JQ, Poo M-M (2007) Calcium signaling in neuronal motility. Annu Rev Cell Dev Biol 23:375-404. doi:10.1146/ annurev.cellbio.23.090506.123221

49. Guan C, Xu H, Jin M, Yuan X, Poo M (2007) Long-range $\mathrm{Ca}^{2+}$ signaling from growth cone to soma mediates reversal of neuronal migration induced by slit-2. Cell 129:385-395. doi:10. 1016/j.cell.2007.01.051

50. Huang Z, Wang Y, Su Z, Geng J-G, Chen Y, Yuan X-B, He C (2011) Slit-2 repels the migration of olfactory ensheathing cells by triggering $\mathrm{Ca}^{2+}$-dependent cofilin activation and RhoA inhibition. J Cell Sci 124:186-197. doi:10.1242/jcs.071357

51. Belgacem YH, Borodinsky LN (2011) Sonic hedgehog signaling is decoded by calcium spike activity in the developing spinal cord. Proc Natl Acad Sci USA 108:4482-4487. doi:10.1073/ pnas. 1018217108

52. Shirasaki R, Katsumata R, Murakami F (1998) Change in chemoattractant responsiveness of developing axons at an intermediate target. Science 279:105-107. doi:10.1126/science. 279.5347.105

53. Nishiyama M, Hoshino A, Tsai L, Henley JR, Goshima Y, Tessier-Lavigne M, Poo M-M, Hong K (2003) Cyclic AMP/ GMP-dependent modulation of $\mathrm{Ca}^{2+}$ channels sets the polarity of nerve growth-cone turning. Nature 423:990-995. doi:10. 1038/nature01751

54. Yacubova E, Komuro H (2002) Intrinsic program for migration of cerebellar granule cells in vitro. J Neurosci 22:5966-5981 
55. Kumada T, Jiang Y, Kawanami A, Cameron DB, Komuro H (2009) Autonomous turning of cerebellar granule cells in vitro by intrinsic programs. Dev Biol 326:237-249. doi:10.1016/j. ydbio.2008.11.012

56. Katz LC, Shatz CJ (1996) Synaptic activity and the construction of cortical circuits. Science 274:1133-1138. doi:10.1126/sci ence.274.5290.1133

57. Sanes JR, Lichtman JW (2001) Induction, assembly, maturation and maintenance of a postsynaptic apparatus. Nat Rev Neurosci 2:791-805. doi:10.1038/35097557

58. Nithianantharajah J, Hannan AJ (2006) Enriched environments, experience-dependent plasticity and disorders of the nervous system. Nat Rev Neurosci 7:697-709. doi:10.1038/nrn1970

59. Lepousez G, Valley MT, Lledo P-M (2013) The impact of adult neurogenesis on olfactory bulb circuits and computations. Annu Rev Physiol 75:339-363. doi:10.1146/annurev-physiol-030212183731

60. Lledo P-M, Merkle FT, Alvarez-Buylla A (2008) Origin and function of olfactory bulb interneuron diversity. Trends Neurosci 31:392-400. doi:10.1016/j.tins.2008.05.006

61. Whitman MC, Greer CA (2009) Adult neurogenesis and the olfactory system. Prog Neurobiol 89:162-175. doi:10.1016/j. pneurobio.2009.07.003

62. Adam Y, Mizrahi A (2010) Circuit formation and maintenanceperspectives from the mammalian olfactory bulb. Curr Opin Neurobiol 20:134-140. doi:10.1016/j.conb.2009.11.001

63. Kaneko N, Marín O, Koike M, Hirota Y, Uchiyama Y, Wu JY, $\mathrm{Lu} \mathrm{Q}$, Tessier-Lavigne M, Alvarez-Buylla A, Okano H, Rubenstein JLR, Sawamoto K (2010) New neurons clear the path of astrocytic processes for their rapid migration in the adult brain. Neuron 67:213-223. doi:10.1016/j.neuron.2010.06.018

64. Sakamoto M, Imayoshi I, Ohtsuka T, Yamaguchi M, Mori K, Kageyama R (2011) Continuous neurogenesis in the adult forebrain is required for innate olfactory responses. Proc Natl Acad Sci USA 108:8479-8484. doi:10.1073/pnas. 1018782108

65. Rochefort C, Gheusi G, Vincent J-D, Lledo P-M (2002) Enriched odor exposure increases the number of newborn neurons in the adult olfactory bulb and improves odor memory. J Neurosci 22:2679-2689

66. Saghatelyan A, Roux P, Migliore M, Rochefort C, Desmaisons D, Charneau P, Shepherd GM, Lledo PM (2005) Activity-dependent adjustments of the inhibitory network in the olfactory bulb following early postnatal deprivation. Neuron 46:103-116. doi:10.1016/j.neuron.2005.02.016

67. Yamaguchi M, Mori K (2005) Critical period for sensory experience-dependent survival of newly generated granule cells in the adult mouse olfactory bulb. Proc Natl Acad Sci USA 102:9697-9702. doi:10.1073/pnas.0406082102

68. Livneh Y, Feinstein N, Klein M, Mizrahi A (2009) Sensory input enhances synaptogenesis of adult-born neurons. J Neurosci 29:86-97. doi:10.1523/JNEUROSCI.4105-08.2009

69. Lin CW, Sim S, Ainsworth A, Okada M, Kelsch W, Lois C (2010) Genetically increased cell-intrinsic excitability enhances neuronal integration into adult brain circuits. Neuron 65:32-39. doi:10.1016/j.neuron.2009.12.001

70. Yoshihara S, Takahashi H, Nishimura N, Naritsuka H, Shirao T, Hirai H, Yoshihara Y, Mori K, Stern PL, Tsuboi A (2012) 5T4 glycoprotein regulates the sensory input-dependent development of a specific subtype of newborn interneurons in the mouse olfactory bulb. J Neurosci 32:2217-2226. doi:10.1523/JNEUR OSCI.5907-11.2012

71. Yoshihara S, Takahashi H, Nishimura N, Kinoshita M, Asahina R, Kitsuki M, Tatsumi K, Furukawa-Hibi Y, Hirai H, Nagai T, Yamada K, Tsuboi A (2014) Npas4 regulates Mdm2 and thus Dcx in experience-dependent dendritic spine development of newborn olfactory bulb interneurons. Cell Rep 8:843-857. doi:10.1016/j.celrep.2014.06.056

72. Lin Y, Bloodgood BL, Hauser JL, Lapan AD, Koon AC, Kim T-K, Hu LS, Malik AN, Greenberg ME (2008) Activity-dependent regulation of inhibitory synapse development by Npas4. Nature 455:1198-1204. doi:10.1038/nature07319

73. Maya-Vetencourt JF, Tiraboschi E, Greco D, Restani L, Cerri C, Auvinen P, Maffei L, Castrén E (2012) Experience-dependent expression of NPAS4 regulates plasticity in adult visual cortex. J Physiol 590:4777-4787. doi:10.1113/jphysiol.2012.234237

74. Pruunsild P, Sepp M, Orav E, Koppel I, Timmusk T (2011) Identification of cis-elements and transcription factors regulating neuronal activity-dependent transcription of human BDNF gene. J Neurosci 31:3295-3308. doi:10.1523/JNEUROSCI.4540-10. 2011

75. Ramamoorthi K, Fropf R, Belfort GM, Fitzmaurice HL, McKinney RM, Neve RL, Otto T, Lin Y (2011) Npas4 regulates a transcriptional program in $\mathrm{CA} 3$ required for contextual memory formation. Science 334:1669-1675. doi:10.1126/sci ence. 1208049

76. Bloodgood BL, Sharma N, Browne HA, Trepman AZ, Greenberg ME (2013) The activity-dependent transcription factor NPAS4 regulates domain-specific inhibition. Nature 503:121-125. doi:10.1038/nature 12743

77. Dickson BJ, Zou Y (2010) Navigating intermediate targets: the nervous system midline. Cold Spring Harb Perspect Biol 2:a002055. doi:10.1101/cshperspect.a002055

78. Schnorrer F, Dickson BJ (2004) Axon guidance: morphogens show the way. Curr Biol 14:R19-R21. doi:10.1016/j.cub.2003. 12.016

79. Dickson BJ (2002) Molecular mechanisms of axon guidance. Science 298:1959-1964. doi:10.1126/science.1072165

80. Black DL, Zipursky SL (2008) To cross or not to cross: alternatively spliced forms of the Robo3 receptor regulate discrete steps in axonal midline crossing. Neuron 58:297-298. doi:10. 1016/j.neuron.2008.04.019

81. López-Bendito G, Cautinat A, Sánchez JA, Bielle F, Flames N, Garratt AN, Talmage DA, Role LW, Charnay P, Marín O, Garel $S$ (2006) Tangential neuronal migration controls axon guidance: a role for Neuregulin-1 in thalamocortical axon navigation. Cell 125:127-142. doi:10.1016/j.cell.2006.01.042

82. Schmid RS, Maness PF (2008) L1 and NCAM adhesion molecules as signaling coreceptors in neuronal migration and process outgrowth. Curr Opin Neurobiol 18:245-250. doi:10.1016/j. conb.2008.07.015

83. Bai G, Pfaff SL (2011) Protease regulation: the Yin and Yang of neural development and disease. Neuron 72:9-21. doi:10.1016/j. neuron.2011.09.012

84. Dudanova I, Klein R (2013) Integration of guidance cues: parallel signaling and crosstalk. Trends Neurosci 36:295-304. doi:10.1016/j.tins.2013.01.007

85. Leyva-Díaz E, Del Toro D, Menal MJ, Cambray S, Susín R, Tessier-Lavigne M, Klein R, Egea J, López-Bendito G (2014) FLRT3 is a Robo1-interacting protein that determines netrin-1 attraction in developing axons. Curr Biol 24:494-508. doi:10. 1016/j.cub.2014.01.042

86. Molnár Z, Garel S, López-Bendito G, Maness P, Price DJ (2012) Mechanisms controlling the guidance of thalamocortical axons through the embryonic forebrain. Eur J Neurosci 35:1573-1585. doi:10.1111/j.1460-9568.2012.08119.x

87. Bielle F, Marcos-Mondéjar P, Leyva-Díaz E, Lokmane L, Mire E, Mailhes C, Keita M, García N, Tessier-Lavigne M, Garel S, López-Bendito G (2011) Emergent growth cone responses to combinations of Slit1 and Netrin 1 in thalamocortical axon topography. Curr Biol 21:1748-1755. doi:10.1016/j.cub.2011. 09.008 
88. Egea J, Erlacher C, Montanez E, Burtscher I, Yamagishi S, Heß M, Hampel F, Sanchez R, Rodriguez-Manzaneque MT, Bösl MR, Fässler R, Lickert H, Klein R (2008) Genetic ablation of FLRT3 reveals a novel morphogenetic function for the anterior visceral endoderm in suppressing mesoderm differentiation. Genes Dev 22:3349-3362. doi:10.1101/gad.486708

89. Maretto S, Müller PS, Aricescu AR, Cho KWY, Bikoff EK, Robertson EJ (2008) Ventral closure, headfold fusion and definitive endoderm migration defects in mouse embryos lacking the fibronectin leucine-rich transmembrane protein FLRT3. Dev Biol 318:184-193. doi:10.1016/j.ydbio.2008.03.021

90. Müller P-S, Schulz R, Maretto S, Costello I, Srinivas S, Bikoff E, Robertson E (2011) The fibronectin leucine-rich repeat transmembrane protein Flrt2 is required in the epicardium to promote heart morphogenesis. Development 138:1297-1308. doi: $10.1242 / \mathrm{dev} .059386$

91. Robinson M, Parsons Perez MC, Tébar L, Palmer J, Patel A, Marks D, Sheasby A, De Felipe C, Coffin R, Livesey FJ, Hunt SP (2004) FLRT3 is expressed in sensory neurons after peripheral nerve injury and regulates neurite outgrowth. Mol Cell Neurosci 27:202-214. doi:10.1016/j.mcn.2004.06.008

92. Tsuji L, Yamashita T, Kubo T, Madura T, Tanaka H, Hosokawa K, Tohyama M (2004) FLRT3, a cell surface molecule containing LRR repeats and a FNIII domain, promotes neurite outgrowth. Biochem Biophys Res Commun 313:1086-1091. doi:10.1016/j.bbrc.2003.12.047

93. Karaulanov E, Böttcher RT, Stannek P, Wei W, Rau M, Ogata S, Cho KWY, Niehrs C (2009) Unc5B interacts with FLRT3 and Rnd1 to modulate cell adhesion in Xenopus embryos. PLoS ONE 4:e5742. doi:10.1371/journal.pone.0005742

94. Yamagishi S, Hampel F, Hata K, Del Toro D, Schwark M, Kvachnina E, Bastmeyer M, Yamashita T, Tarabykin V, Klein R, Egea J (2011) FLRT2 and FLRT3 act as repulsive guidance cues for Unc5-positive neurons. EMBO J 30:2920-2933. doi:10. 1038/emboj.2011.189

95. Seiradake E, del Toro D, Nagel D, Cop F, Härtl R, Ruff T, SeyitBremer G, Harlos K, Border EC, Acker-Palmer A, Jones EY, Klein R (2014) FLRT structure: balancing repulsion and cell adhesion in cortical and vascular development. Neuron 84:370-385. doi:10.1016/j.neuron.2014.10.008

96. O'Sullivan ML, de Wit J, Savas JN, Comoletti D, Otto-Hitt S, Yates JR, Ghosh A (2012) FLRT proteins are endogenous latrophilin ligands and regulate excitatory synapse development. Neuron 73:903-910. doi:10.1016/j.neuron.2012.01.018

97. Bouchard J-F, Moore SW, Tritsch NX, Roux PP, Shekarabi M, Barker PA, Kennedy TE (2004) Protein kinase A activation promotes plasma membrane insertion of DCC from an intracellular pool: a novel mechanism regulating commissural axon extension. J Neurosci 24:3040-3050. doi:10.1523/JNEUROSCI. 4934-03.2004

98. Fothergill T, Donahoo ALS, Douglass A, Zalucki O, Yuan J, Shu T, Goodhill GJ, Richards LJ (2014) Netrin-DCC signaling regulates corpus callosum formation through attraction of pioneering axons and by modulating slit2-mediated repulsion. Cereb Cortex 24:1138-1151. doi:10.1093/cercor/bhs395
99. Stein E, Tessier-Lavigne M (2001) Hierarchical organization of guidance receptors: silencing of netrin attraction by slit through a Robo/DCC receptor complex. Science 291:1928-1938. doi:10. 1126/science. 1058445

100. Adams RH, Alitalo K (2007) Molecular regulation of angiogenesis and lymphangiogenesis. Nat Rev Mol Cell Biol 8:464-478. doi:10.1038/nrm2183

101. Adams RH, Eichmann A (2010) Axon guidance molecules in vascular patterning. Cold Spring Harb Perspect Biol 2:a001875. doi:10.1101/cshperspect.a001875

102. Eichmann A, Makinen T, Alitalo K (2005) Neural guidance molecules regulate vascular remodeling and vessel navigation. Genes Dev 19:1013-1021. doi:10.1101/gad.1305405

103. Lu X, Le Noble F, Yuan L, Jiang Q, De Lafarge B, Sugiyama D, Bréant C, Claes F, De Smet F, Thomas J-L, Autiero M, Carmeliet P, Tessier-Lavigne M, Eichmann A (2004) The netrin receptor UNC5B mediates guidance events controlling morphogenesis of the vascular system. Nature 432:179-186. doi:10. 1038/nature03080

104. Larrivée B, Freitas C, Trombe M, Lv X, DeLafarge B, Yuan L, Bouvrée K, Bréant C, Del Toro R, Bréchot N, Germain S, Bono F, Dol F, Claes F, Fischer C, Autiero M, Thomas JL, Carmeliet P, Tessier-Lavigne M, Eichmann A (2007) Activation of the UNC5B receptor by Netrin-1 inhibits sprouting angiogenesis. Genes Dev 21:2433-2447. doi:10.1101/gad.437807

105. Koch AW, Mathivet T, Larrivée B, Tong RK, Kowalski J, Pibouin-Fragner L, Bouvrée K, Stawicki S, Nicholes K, Rathore N, Scales SJ, Luis E, del Toro R, Freitas C, Bréant C, Michaud A, Corvol P, Thomas JL, Wu Y, Peale F, Watts RJ, TessierLavigne M, Bagri A, Eichmann A (2011) Robo4 maintains vessel integrity and inhibits angiogenesis by interacting with UNC5B. Dev Cell 20:33-46. doi:10.1016/j.devcel.2010.12.001

106. Navankasattusas S, Whitehead KJ, Suli A, Sorensen LK, Lim AH, Zhao J, Park KW, Wythe JD, Thomas KR, Chien C-B, Li DY (2008) The netrin receptor UNC5B promotes angiogenesis in specific vascular beds. Development 135:659-667. doi:10. 1242/dev.013623

107. Li YN, Pinzón-Duarte G, Dattilo M, Claudepierre T, Koch M, Brunken WJ (2012) The expression and function of netrin-4 in murine ocular tissues. Exp Eye Res 96:24-35. doi:10.1016/j. exer.2012.01.007

108. Lejmi E, Leconte L, Pédron-Mazoyer S, Ropert S, Raoul W, Lavalette S, Bouras I, Feron J-G, Maitre-Boube M, Assayag F, Feumi C, Alemany M, Jie TX, Merkulova T, Poupon M-F, Ruchoux M-M, Tobelem G, Sennlaub F, Plouët J (2008) Netrin4 inhibits angiogenesis via binding to neogenin and recruitment of Unc5B. Proc Natl Acad Sci USA 105:12491-12496. doi:10. 1073/pnas.0804008105

109. Hayano Y, Sasaki K, Ohmura N, Takemoto M, Maeda Y, Yamashita T, Hata Y, Kitada K, Yamamoto N (2014) Netrin-4 regulates thalamocortical axon branching in an activity-dependent fashion. Proc Natl Acad Sci USA 111:15226-15231. doi:10.1073/pnas.1402095111 